\title{
General Features of Three Common Types of Cancer In a Southern Province of Turkey: Data From Antalya Province
}

\author{
Alparslan Merdin, Hülya Karakılınç, Hakan Şat Bozcuk
}

\begin{abstract}
Background \& Aims: We aimed to evaluate the general features of three common types of cancer in a southern province of Turkey. Methods: All patients were diagnosed with malignancy between the years 2005 and 2010 (the year 2005 and 2010 included), and registered by Antalya Provincial Health Directorate Cancer Registry Center (Antalya İl Sağlık Müdürlüğü Kanser Kayıt Merkezi) (AİSMKKM).The study included patients diagnosed with breast, lung or prostate cancer between the defined time interval and patients with a history of breast, lung or prostate cancer followed by a subsequent malignancy diagnosed between the defined time interval. The study was a retrospective study. The study included 1977 breast cancer patients, 2680 lung cancer patients and 1840 prostate cancer patients. All the data included in the study were given by AİSMKKM. We stratified data according to age, sex, stage and subtype of primary tumor of the patients. Results: 1442 of the patients with breast cancer had invasive ductal type. Median age at the time of diagnosis were 51, 62, 69 for breast, lung and prostate cancer patients, respectively. Lastly, percentage of patients with advanced metastatic disease at the time of diagnosis for breast, lung and prostate cancer patients were $8.74 \%, 60.5 \%$ and $11.85 \%$, respectively. Conclusion: People should be encouraged to participate in screening programs.
\end{abstract}

Index Terms - Southern province, general features, common types of cancer, Mediterranean Region, Turkey.

\section{INTRODUCTION}

The most common cancers worldwide are prostate cancer in males and breast cancer in females. The incidence of prostate cancer could vary in different regions of the world. The reasons for this might include the genetic origins of prostate cancer and development level of health services. Due to prolongation of life expectancy in the developed countries, as well as advanced medical practices and screening methods, the prevalence of the disease might change. Breast cancer is major oncological problem in women. There are well known risk factors for breast cancer. Some inherited genetic mutations could also predispose breast cancer. Cancer could develop from both lobular and ductal parts of the breast. There is great survival benefit in case of early detection for breast cancer. Breast cancer screening is therefore important. The prevalence of breast cancer could also vary from region to region. The reasons for this variability might include dietary habits, genetic factors, screening programs, socioeconomic status and environmental impacts.

Alparslan Merdin, University of Akdeniz, Department of Internal Medicine, Antalya, Turkey

Hulya Karakılınc, Antalya İl Sağlık Müdürlüğü, Antalya, Turkey Hakan Sat Bozcuk, University of Akdeniz, Department of Internal Medicine, Division of Oncology, Turkey
Lung cancer is one of the most common cancer caused death reason. The most common cause of lung cancer is cigarette smoking. There is not a screening method used for lung cancer. Decreased smoking rates in the population could also result in decreased number of lung cancer patients. Hereby, our study aimed to evaluate the general features of three common types of cancer in a southern province of Turkey.

\section{MATERIALS AND METHODS}

All patients were diagnosed with malignancy between the years 2005 and 2010 (the year 2005 and 2010 included), and registered by Antalya Provincial Health Directorate Cancer Registry Center (Antalya İl Sağlık Müdürlüğü Kanser Kayıt Merkezi) (AİSMKKM). The study included patients diagnosed with breast, lung or prostate cancer between the defined time interval and patients with a history of breast, lung or prostate cancer followed by a subsequent malignancy diagnosed between the defined time interval. The study was a retrospective study. The study included 1977 breast cancer patients, 2680 lung cancer patients and 1840 prostate cancer patients. All the data included in the study were given by AISMKKM in the year 2012. We stratified data according to age, sex, stage and subtype of primary tumor.

Our study was a retrospective study. The data obtained were classified based on age, gender, tumor stage and tumor subtypes. The tumor data found at AISMKKM had been collected in accordance with the Surveillance, Epidemiology, and End Results (SEER) program. In our study, tumor stages were categorized as metastatic and non-metastatic based on the SEER staging system. Tumor stages of the some patients included in the study were not found in the database given by the AISMKKM. Therefore, the percentages about the tumor stages were estimated over the found data. The statistical analysis of the research data was conducted using SPSS 18 (Statistical Package for Social Science). The study protocol was approved by the local ethics committee.

\section{RESULTS}

$130(6.6 \%)$ of the breast cancer patients had invasive lobular cancer, 1442 (72.9\%) invasive ductal, 87 (4.4\%) mixed type and $318(16.1 \%)$ patients had other types of breast cancer (Table 1). $27(1.36 \%)$ of breast cancer patients were males. Of the lung cancers, 375 (14\%) were small cell carcinoma, 1807 (67.4\%) non-small cell carcinoma, and 498 (18.6\%) other types of lung cancer (Table 1). While 1745 (94.84\%) of the prostate cancer patients had prostate adenocarcinoma, $95(16.5 \%)$ were classified as the other type of prostate cancer (Table 1). 
Table 1. Distribution of histological subtypes of breast, lung and prostate cancer

\begin{tabular}{lcc} 
Histological Subtypes & $\mathbf{N}$ & \multicolumn{1}{c}{$\%$} \\
\hline Breast Cancer & $\mathbf{1 3 0}$ & $\mathbf{1 4 2}$ \\
Invasive Lobular Breast Cancer & $\mathbf{8 7}$ & 72.9 \\
Invasive Ductal Breast Cancer & $\mathbf{3 1 8}$ & 4.4 \\
Mixed Type Breast Cancer & & 16.1 \\
Other & $\mathbf{1 7 4 5}$ & $\mathbf{9 5}$ \\
Prostate Cancer & 94.84 \\
Prostate Adenocarcinoma & 5.16 \\
Other & $\mathbf{1 8 0 7}$ \\
Lung Cancer & $\mathbf{3 7 5}$ & $\mathbf{4 9 8}$
\end{tabular}

The median patient age at diagnosis in patients with breast, lung and prostate cancer was 51, 62 and 69, respectively (Table 2). The number of patients with metastatic disease at diagnosis of breast, lung and prostate cancer, were $135(8.74 \%$ of the patients with the known tumor stage status ), 1.195 (60.5\% of the patients with the known tumor stage status) and 146 (11.85\% of the patients with the known tumor stage status), respectively (Table 2).

Table 2. General features of patients with breast, lung and prostate cancer

\begin{tabular}{|c|c|c|c|}
\hline $\begin{array}{l}\text { Demographic } \\
\text { Characteristics }\end{array}$ & $\begin{array}{c}\text { Lung Cancer } \\
\text { N }(\%)\end{array}$ & $\begin{array}{c}\text { Breast Cancer } \\
\mathbf{N}(\%) \\
\end{array}$ & $\begin{array}{c}\text { Prostate Cance } \\
\text { N }(\%)\end{array}$ \\
\hline \multicolumn{4}{|l|}{ Gender } \\
\hline Male & $2316(86.4)$ & $27(1.36)$ & $1840(100)$ \\
\hline Female & 364 (13.6) & $1950(98.64)$ & \\
\hline \multicolumn{4}{|l|}{ Age } \\
\hline Mean & 61.6 & 52.2 & 68.2 \\
\hline Median & 62 & 51 & 69 \\
\hline \multicolumn{4}{|c|}{$\begin{array}{c}\text { Disease Stage at Diagnosis } \\
\text { Stage IV }\end{array}$} \\
\hline \multirow[t]{2}{*}{ Other } & 1195 (60.5) & $135(8.74)$ & $146(11.85)$ \\
\hline & 779 (39.5) & $1411(91.26)$ & $1086(88.15)$ \\
\hline
\end{tabular}

\section{DISCUSSION}

Prostate cancer is the most common cancer among men. The median age of prostate cancer patients in the United States was reported as 67 years old(1,2). In our study, we found a slightly higher median age, 69 , in the prostate cancer patients living in Antalya, as compared to the relevant American data. Besides, the previous work in the literature reported that $4 \%$ of prostate cancer patients had metastatic disease at diagnosis(3). The current study results showed that $11.85 \%$ of our prostate cancer patients had metastatic disease at the time of diagnosis. In light of these findings, we can suggest that prostate cancer patients in Antalya region receive diagnosis in older ages and relatively more advanced stages. We consider that these results might be due to lack of widespread population screening programs. Development risk of prostate cancer might also be associated with factors other than genetic factors(4). Diets rich in saturated fat might contribute to the risk of prostate cancer(4).

Breast cancer is the most common cancer in women. Prolonged exposure to estrogen hormone, obesity, high-fat diet, early menarche and late menopause, having fewer children, non-breastfeeding and oral contraceptive use might increase the risk of breast cancer. In our study, the median age of breast cancer diagnosis was 61 years. On the other side, lung cancer is a common cause of cancer death in the world. In the United States, the median age of patients at lung cancer 
diagnosis was reported as 70 years old $(1,2)$. On the other hand, the median age of lung cancer cases in our study was 62 years old, which indicates a much younger median age at diagnosis in our country. The reason for this might be the higher rate of smoking. In addition to this, based on the data from Antalya, $60 \%$ of the lung cancer patients in our study had metastasis at the time of diagnosis. Our study findings showed that lung cancer patients in Antalya region are often diagnosed at an advanced stage of the disease. Lastly, registration on the AISMKKM database had been going on when the data was given for the study. Further studies including more registrated patients in a longer time interval will help to have more accurate conclusions.

In conclusion, people should be encouraged to participate in screening programs and further studies on cancer data should be carried out.

\section{COMPETING INTERESTS}

There is no conflicts of interest in this study.

ACKNOWLEDGEMENTS

We would like to express our gratitude towards to Cancer Registry Office of Antalya Provincial Directorate Of

Health(AISMKKM) for giving their data in the year 2012.

$$
\text { AUTHORSHIP }
$$

Contribution: A.M., H.K. and H.Ş.B. ; Designed the study : A.M. , H.K. , H.Ş.B ; Gathered Data From The Cancer Registry : H.K. ; Analyzed Data: H.Ş.B. ; Wrote the Manuscript: A.M. and H.Ş.B.

\section{REFERENCES}

[1]. Howlader N, Noone AM, Krapcho M, et al. SEER Cancer Statistics Review, 1975-2009 (Vintage 2009 Populations). Bethesda, MD: National Cancer Institute; based on November 2011 SEER data submission, posted to the SEER web site, April 2012.

[2]http://seer.cancer.gov/csr/1975_2009_pops09/results_single/sect_01_tab le.11_2pgs.pdf

[3] Paquette EL, Sun L, Paquette LR, et al: Improved prostate cancer-specific survival and other disease parameters: impact of prostate-specific antigen testing. Urology 2002; 60: 756-759

[4]Whittemore AS, Kolonel LN, Wu AH, et al. Prostate cancer in relation to diet, physical activity, and body size in blacks, whites, and Asians in the United States and Canada. J Natl Cancer Inst 1995;87: 652-661 